Corrigendum

\title{
Corrigendum to "A Theoretical Argument Why the t-Copula Explains Credit Risk Contagion Better than the Gaussian Copula"
}

\author{
Didier Cossin, ${ }^{1,2,3}$ Henry Schellhorn, ${ }^{1,2,3}$ Nan Song, ${ }^{1,2,3}$ and Sachapon Tungsong ${ }^{1,2,3}$ \\ ${ }^{1}$ IMD, 1001 Lausanne, Switzerland \\ ${ }^{2}$ Claremont Graduate University, Claremont, CA 91711, USA \\ ${ }^{3}$ Thammasat University, Bangkok, Thailand \\ Correspondence should be addressed to Henry Schellhorn; henry.schellhorn@cgu.edu \\ Received 6 November 2016; Accepted 22 November 2016 \\ Copyright (C) 2016 Didier Cossin et al. This is an open access article distributed under the Creative Commons Attribution License, \\ which permits unrestricted use, distribution, and reproduction in any medium, provided the original work is properly cited.
}

In the article titled "A Theoretical Argument Why the tCopula Explains Credit Risk Contagion Better than the Gaussian Copula" [1], the name of the fourth author was given incorrectly as Satjaporn Tungsong. The author's name should have been written as Sachapon Tungsong. The revised authors' list is shown above.

\section{References}

[1] D. Cossin, H. Schellhorn, N. Song, and S. Tungsong, "A theoretical argument why the t-copula explains credit risk contagion better than the Gaussian copula," Advances in Decision Sciences, vol. 2010, Article ID 546547, 29 pages, 2010. 


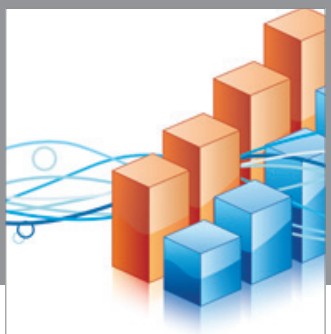

Advances in

Operations Research

vatem alat4

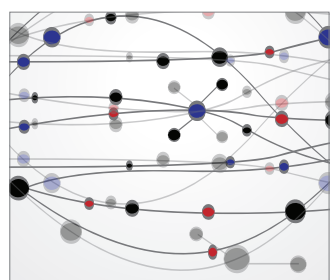

\section{The Scientific} World Journal
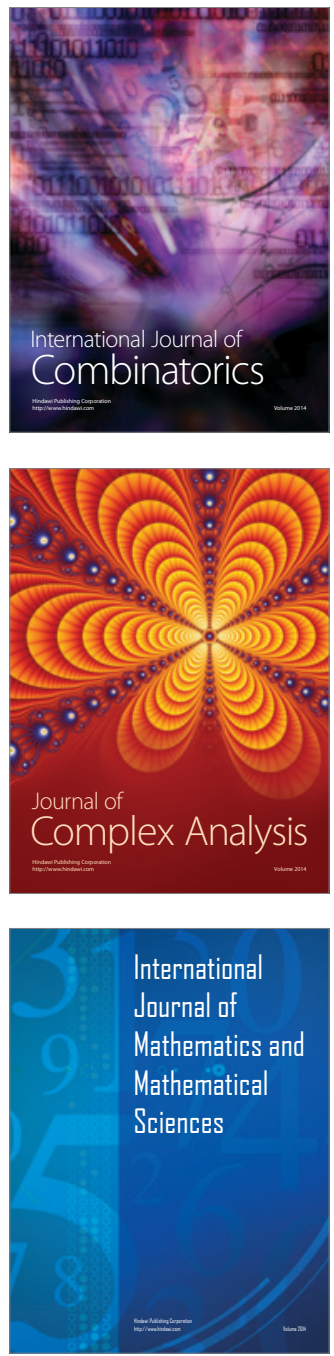
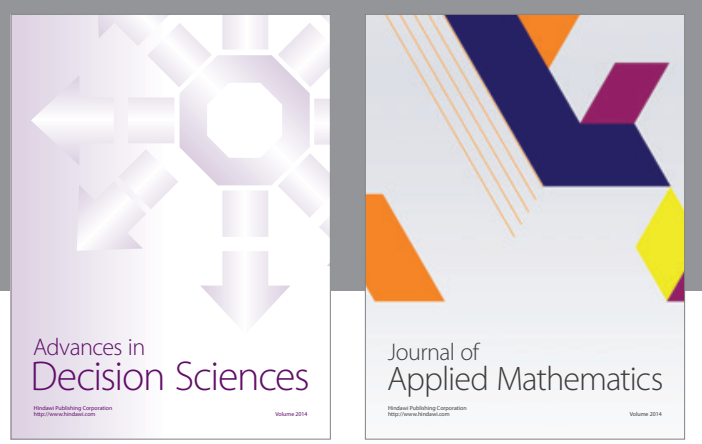

Algebra

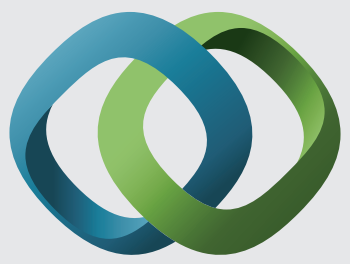

\section{Hindawi}

Submit your manuscripts at

http://www.hindawi.com
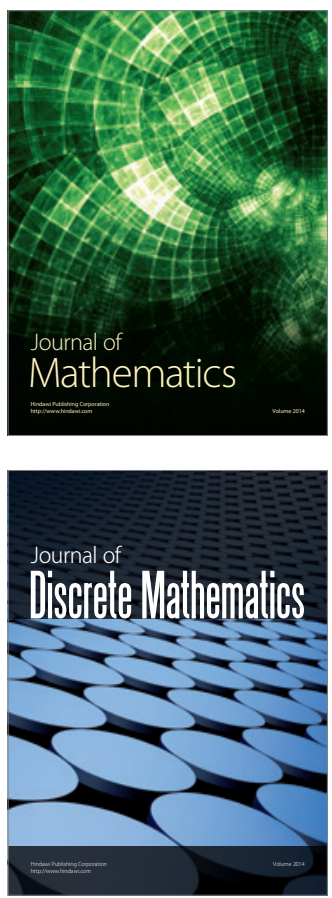

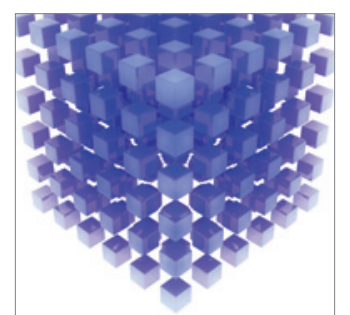

Mathematical Problems in Engineering
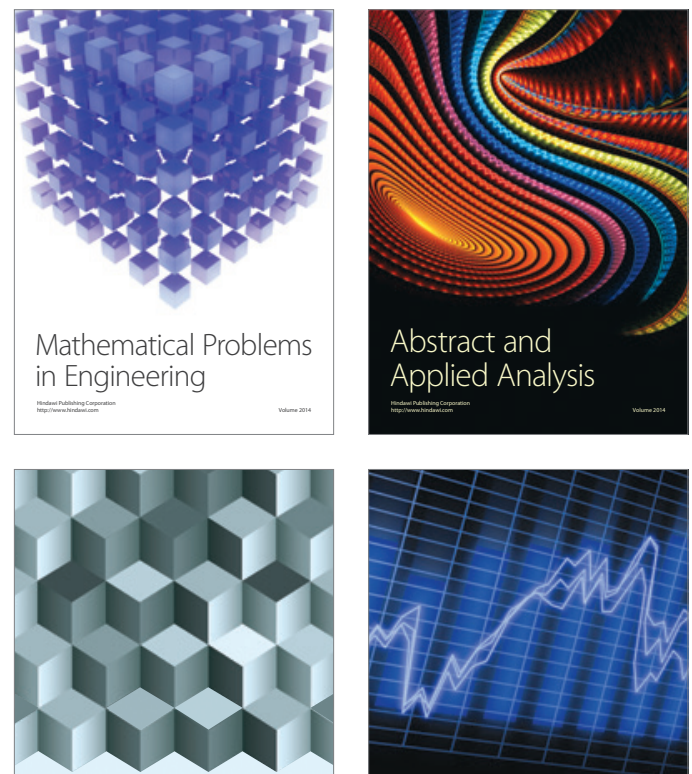

Journal of

Function Spaces

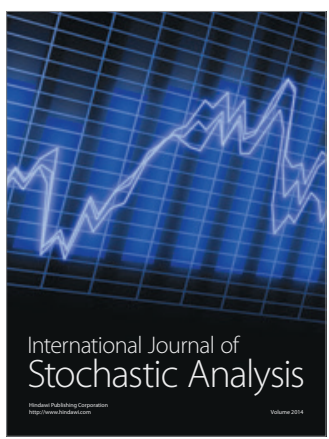

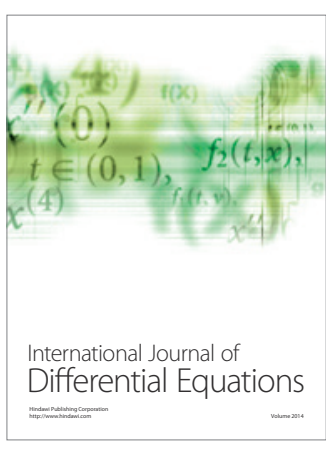
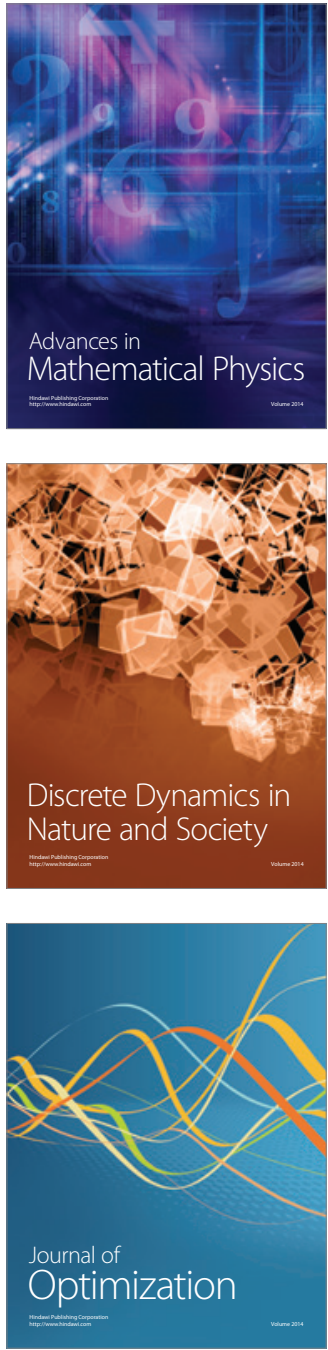